\title{
RELATION OF BODY MASS INDEX AND EARLY COMPLICATIONS FOLLOWING MODIFIED RADICAL MASTECTOMY NAMAN CHANDRAKAR ${ }^{\mathrm{a} 1}$ AND RAJU K. SHINDE ${ }^{\mathrm{b}}$
}

\author{
aSenior Resident Department of General Surgery, AIIMS Raipur, C.G., India

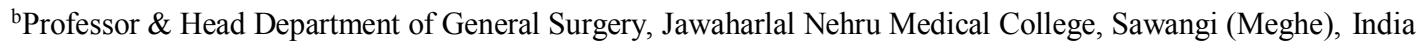

\begin{abstract}
Breast cancer ranges from 19 to $45 \%$ of all cancers among Indian women in various geographical locations. The present Prospective and observational study was conducted in the Department of Surgery of Acharya Vinoba Bhave Rural Hospital attached to Jawaharlal Nehru Medical College. Forty one patients of carcinoma breast were treated with Modified Radical Mastectomy from September 2013 to September 2015.The mean age of cases was 50.90 years with a standard deviation of 11.61 years. only 1 male patient $(2.44 \%)$ was diagnosed with carcinoma breast and 40 female patients $(97.56 \%)$ out of 41 total cases. Maximum cases i.e $13(31.70 \%)$ had involvement of upper outer quadrant. The number of cases with normal BMI was 24 (56.10\%) and 17 cases $(41.46 \%)$ were overweight. The mean BMI was 24.35 with standard deviation of 2.48 . Significant association was found between BMI and incidence of wound dehiscence (p value-0.014). Significant association was found between BMI and seroma (p value-0.003). Significant association was found between BMI and haematoma (p value-0.033). There was no statistically significant association found between BMI and flap necrosis ( $p$ value- 0.934$)$, altered sensation ( $p$ value- 0.57 ) and pain $(p$ value0.22) It was concluded that increased BMI one of the most common risk factors for early complications like seroma, hematoma and wound dehiscence, after Modified Radical Mastectomy.
\end{abstract}

KEYWORDS: Body mass Index, seroma, hematoma, wound dehiscence, Modified Radical Mastectomy

The number of breast cancer cases is rising rapidly in India. It is reported that one in 22 women in India are likely to get breast cancer during the life time. This number is definitely high among American women; one in eight being the victim of this disease. (Ferlay et al., 2013)

The modern approach to breast cancer management is multidisciplinary which includes surgery, radiotherapy, hormonal therapy and chemotherapy. (Clifford et al., 1997) However, surgical management is the hallmark of treatment of breast cancer. Among the surgical procedures modified radical mastectomy (MRM) is the most commonly performed procedure. (Thompson, 1999)

Early complications are defined here as complications occurring within 30 days after surgery. It is documented that early wound complications after modified radical mastectomy include wound infections, seromas, lymphoedema, chronic pain, flap necrosis and hematomas. Based on different conducted surveys, a wide range of 0.8 $26 \%$ has been reported as the incidence rate of the surgical site complications after the breast surgeries. (Hynes, 2004 and Prospero et al., 2006)

Seroma formation is the most frequent postoperative complication seen after modified radical mastectomy with an incidence of $3 \%$ to $85 \%$. (RuvalcabaLimón et al., 2006) Age, body mass index, history of prior neoadjuvant chemotherapy, stage of the disease according to TNM and the volume of seroma collected during the first 24 postoperative hours have an influence on seroma formation and may be considered as seroma formation prognostic factors in patients undergoing modified radical mastectomy. (Kumar et al., 1995)

Infection developing within seroma increases morbidity and often results in the need for re-admission, reimaging, drainage and antibiotic usage. (Zieliński et al., 2013)

In the present institute many patients present from rural areas with advanced stage of malignancy and patients from urban area with raised body mass index. Hence, the present study was undertaken to study the complications and their relation with body mass index and chemotherapy which was given for advanced malignancy so that these complications can be refined.

\section{MATERIALS AND METHODS}

The present Prospective and observational study entitled "Relation of body mass index and early complications following modified radical mastectomy" was conducted in the Department of Surgery of Acharya Vinoba 
Bhave Rural Hospital attached to Jawaharlal Nehru Medical College. Duration of study was 2 years i.e September 2013 to September 2015. Forty one patients of carcinoma breast were treated with Modified Radical Mastectomy from September 2013 to September 2015.

\section{Inclusion Criteria}

1. All the patients who undergo modified radical mastectomy procedure.

\section{Exclusion Criteria}

1. Pre-existing pain at operative site or on the contralateral site.

2. Patients on anticoagulants/aspirin.

3. Patients with malignant breast carcinoma.

\section{Method of Collection of Data}

Data was collected from a especially designed case recording proforma pertaining to patient particulars, examinations, diagnosis. Post-operative complications were noted on day $4^{\text {th }}$, day $10^{\text {th }}$ and in 1 month follow up. It was then subjected to statistical analysis with the help of biostatistician of our institute. Before start of our study a written consent was obtained in local vernacular in each patient.

\section{Procedure}

The modified radical mastectomy removes all breast tissue, the nipple areola complex, necessary skin, and level I and level II axillary lymph nodes. In suspicious cases level III axillary lymph nodes were removed. Negative suction drain was kept in situ in the axilla and beneath flaps.

Drain was kept for a minimum of 3 days and it was removed on the day when 24 hour drain output was less than $20 \mathrm{ml}$. the drain was strictly removed on $7^{\text {th }}$ day irrespective of the amount of drain output.

\section{Statistical Analysis}

Statistical analysis was done by using descriptive and inferential statistics using Chisquare test and software used in the analysis were SPSS17.0 version and Graph Pad Prism 5.0 and $p<0.05$ is considered as level of significance $(\mathrm{p}<0.05)$.

\section{RESULTS}

Sixteen cases $(39.02 \%)$ belonged to the age group 51-60 years, $11(26.83 \%)$ cases in the age group of $31-40$ years, $8(19.51 \%)$ cases in $41-50$ years and $5(12.20 \%)$ cases were above 60 years of age. The mean age of cases was 50.90 years with a standard deviation of 11.61 years. The youngest patient was of 30 years and oldest of 75 years. Only one patient (2.44\%) was diagnosed with carcinoma breast at the age of 30 years.

In the present study, only 1 male patient $(2.44 \%)$ was diagnosed with carcinoma breast and 40 female patients $(97.56 \%)$ out of 41 total cases.

In all the 41 cases $(100 \%)$ chief complaint was lump in breast, followed by axillary swelling in 11 cases (26.83\%) and history of pain (in lump) in 8 cases (19.51\%).

Table 1: Distribution of patients according to presenting complaints

\begin{tabular}{|c|c|c|}
\hline Presenting complaints & No of patients & $\mathbf{( \% )}$ \\
\hline Lump in breast & 41 & 100 \\
\hline Pain in lump & 8 & 19.51 \\
\hline Axillary Swelling & 11 & 26.83 \\
\hline
\end{tabular}

There were 21 cases $(51.22 \%)$ with involvement of right breast as compared to left in 20 cases $(48.78 \%)$ ).

Maximum cases i.e $13(31.70 \%)$ had involvement of upper outer quadrant, 7 cases $(17.07 \%)$ had involvement of lower outer quadrant, 6 cases (14.63\%) involved upper inner quadrant, 2 cases $(4.88 \%)$ involved lower inner quadrant. Among the 13 patients who had involvement of more than 1 quadrant included 6 cases (14.63\%) with involvement of upper outer and lower outer quadrant, 4 cases $(9.76 \%)$ with involvement of upper inner and upper outer quadrant, and 3 cases $(7.31 \%)$ had involvement of lower outer and lower inner quadrant.

32 cases $(78.05 \%)$ had tumour more than $2 \mathrm{~cm}$ but not more than $5 \mathrm{~cm}$ in greatest dimension (Table 2) and 8 cases $(19.52 \%)$ had tumour size more than $5 \mathrm{~cm}$ with areas of skin involvement without ulceration or satellite nodules (Table 3$)$. There was only single case $(2.44 \%)$ with tumour size $2 \mathrm{~cm}$ (Table 1).

The number of cases with normal BMI was 24 $(56.10 \%)$ and 17 cases $(41.46 \%)$ were overweight. The mean BMI was 24.35 with standard deviation of 2.48 . 
CHANDRAKAR AND SHINDE: RELATION OF BODY MASS INDEX AND EARLY COMPLICATIONS FOLLOWING...

Table 2: BMI $(\mathrm{kg} / \mathrm{m} 2)$ wise distribution of patients

\begin{tabular}{|c|c|c|}
\hline BMI $(\mathrm{kg} / \mathrm{m} 2)$ & No of patients & $(\%)$ \\
\hline Normal (18.5-25) & 24 & 56.10 \\
\hline $\begin{array}{c}\text { Overweight } \\
(25.1-29.9)\end{array}$ & 17 & 41.46 \\
\hline Obese $(>30)$ & 0 & 0.00 \\
\hline Total & 41 & 100.00 \\
\hline Mean \pm SD & $24.35 \pm 2.48(19-28 \mathrm{~kg} / \mathrm{m} 2)$ \\
\hline
\end{tabular}

In the present study there were 17 cases $(41.46 \%)$ who were overweight. Significant association was found between BMI and incidence of wound dehiscence ( $\mathrm{p}$ value0.014 ). Total 9 patients had wound dehiscence amongst 17 overweight cases. Total 8 patients had seroma amongst 17 overweight cases. Significant association was found between BMI and seroma ( $\mathrm{p}$ value-0.003). Total 3 patients had haematoma amongst 17 overweight cases. Significant association was found between BMI and haematoma ( $p$ value-0.033). Table 3

There was no statistically significant association found between BMI and flap necrosis ( $\mathrm{p}$ value- 0.934), altered sensation ( $p$ value- 0.57 ) and pain ( $p$ value- 0.22 )

Table 3: Correlation of BMI with complication

\begin{tabular}{|c|c|c|c|c|c|c|}
\hline BMI & Flap Necrosis & $\begin{array}{c}\text { Wound } \\
\text { Dehiscence }\end{array}$ & Seroma & Haematoma & $\begin{array}{c}\text { Altered } \\
\text { Sensation }\end{array}$ & Pain \\
\hline$\leq 25 \mathrm{~kg} / \mathrm{m} 2$ & $4(9.76 \%)$ & $4(9.76 \%)$ & $3(7.32 \%)$ & $0(0 \%)$ & $6(14.63 \%)$ & $0(0 \%)$ \\
\hline$>25 \mathrm{~kg} / \mathrm{m} 2$ & $3(7.32 \%)$ & $9(21.95 \%)$ & $8(19.51 \%)$ & $3(7.32 \%)$ & $3(7.32 \%)$ & $1(2.44 \%)$ \\
\hline Total & $7(17.07 \%)$ & $13(31.71 \%)$ & $11(26.83 \%)$ & $3(7.32 \%)$ & $9(21.95 \%)$ & $1(2.44 \%)$ \\
\hline$\chi^{2}$-value & 0.007 & 6.04 & 8.88 & 4.57 & 0.31 & 1.44 \\
\hline p-value & $0.934, \mathrm{NS}$ & $\begin{array}{c}0.014 \\
\mathrm{~S}, \mathrm{p}<0.05\end{array}$ & $\begin{array}{c}0.003 \\
\mathrm{~S}, \mathrm{p}<0.05\end{array}$ & $\begin{array}{c}0.033 \\
\mathrm{~S}, \mathrm{p}<0.05\end{array}$ & $0.57, \mathrm{NS}$ & $0.22, \mathrm{NS}$ \\
\hline
\end{tabular}

\section{DISCUSSION}

The mean age of cases was 50.90 years with a standard deviation of 11.61 years. In a study of 150 patients by Dahri et al.,, maximum patients was 40-60 year of age with a mean age of 52 year. It is an accepted fact that incidence of carcinoma of male is $1 \%$. In a study of Sandhu et al.,, conducted in India among 304 breast cancer patients found incidence of male breast carcinoma as $1.3 \%$ where as Weiss et al., reported it as $<1 \%$ in his epidemiological study. In present study, all 41 cases $(100 \%)$ presented with lump in the breast, followed by axillary swelling 11 (26.83\%) and pain in breast lump in 8 (19.51\%). Our study is comparable to Sharma V.M. et al.,, who also reported with lump in breast as presenting symptom in all the cases $(100 \%)$. In the present study, out of 41 cases, 21 cases $(51.22 \%)$ had involvement of right breast as compared to left in 20 cases $(48.78 \%)$. Overall in 28 cases breast lump was limited to only one quadrant of breast. In 13 cases tumor was involving more than one quadrant. Maximum 13 had involvement of upper outer quadrant $(31.70 \%), 7$ cases had involvement of lower outer quadrant $(17.07 \%), 6$ cases involved upper inner quadrant (14.63\%), 2 cases involved lower inner quadrant (4.88\%). Among the 13 patients who had involvement of more than one quadrant, distribution of the cases were as follows; 6 cases with involvement of upper outer and lower outer quadrant (14.63\%), 4 cases with involvement of upper inner and upper outer quadrant $(9.76 \%)$, and 3 cases had involvement of lower outer and lower inner quadrant (7.31\%).

Sandhu et al.,, reported that out of the total 304 patients in his study group with 144 patients with lump in the right breast (47.4\%) and 157 patients had a lump in the left breast $(51.6 \%)$ and 3 cases had bilateral breast involvement.

Most common site of tumor location in the breast was in the upper outer quadrant in 148 patients (46.25\%). Upper outer quadrant of the breast is the most frequent site of carcinoma; this basic observation has become textbook fact, and remains true for countries as disparate as India, the West Indies and Italy.

Raju et al.,, in a study of 363 patients reported that upper outer quadrant $(41 \%)$ as the most common site of breast cancer followed by, central (22\%), upper inner quadrant $18 \%$ and lower inner quadrant (11\%). The lower outer quadrant (8\%) was the least involved site. 


\section{CHANDRAKAR AND SHINDE: RELATION OF BODY MASS INDEX AND EARLY COMPLICATIONS FOLLOWING...}

In the present study apart from a single case of $\mathrm{T} 1$ lesions $(2.44 \%)$, maximum number of cases were of $\mathrm{T} 2$ stage $32(78.05 \%)$ and 8 cases of the T3 tumor stage $(19.52 \%)$.

Ghosh et al.,, in a study of 320 patients in India found 164 cases with T2 lesions (51.3\%), 32 cases with T1 lesions (10\%), 82 cases with T3 lesions (25.6\%) and rest 42 cases with T4 stage tumors (13.1\%). Bilal fazal sheikh et $a l$, in his study of 78 patients reported that $1 / 3$ rd $(34.62 \%)$ of the study population were having T2 stage tumors while $51(65.38 \%)$ patients had T3 stage tumors.

In present study the number of cases with normal BMI was $24(56.10 \%)$ and 17 cases (41.46\%) were overweight. The mean BMI was 24.35 with standard deviation of 2.48 .

Statistically significant association of BMI was found with seroma, hematoma and wound dehiscence. The present study correlates with the study conducted by Altinyollar et al., and Jacek Zieliński et al.,

David et al.,, reported significant association of body mass index greater than 25 and diabetes mellitus to SSI as risk factors $(\mathrm{P}<.05)$.

Wound dehiscence was encountered in 4 cases $(9.76 \%)$ with normal BMI and in 9 cases $(13.71 \%)$ in overweight patients. It had statistically significant association with raised BMI of the patient. Significant statistical association was found between stage of the disease ( $p$ value-0.014) and BMI ( $p$ value-0.033) with hematoma. There was no significant association of altered sensation with the BMI.

\section{CONCLUSION}

It was observed that increased BMI had significant association with seroma, hematoma and wound dehiscence suggesting that abnormal BMI leads to various complications. Based on present findings and recent data from meta-analysis we conclude "Increased BMI one of the most common risk factors for early complications like seroma, hematoma and wound dehiscence, after Modified Radical Mastectomy.

\section{REFERENCES}

Altinyollar H., Kapucuoglu N., Pak I. and Berberoglu U., 2000. Lymphatic mapping and sentinel lymphadenectomy in early stage breast carcinoma. Journal of Experimental \& Clinical Cancer Research, 19(2):141-4.

Azzena A., Zen T., Ferrara A., Brunetti V., Vasile C. and Marchetti M., 1994. Risk factors for breast cancer. Eur. J. Gynaecol Oncol, 15: 386-392.

Clifford A. Hudis and Larry Norton. Adjuvant Drug Treatment for Resectable Breast Cancer The Oncologist December 1997. 2(6):351-358.

Dahri F.J., Awan M.S., Qazi A.R., Khaskheli N.M. and Soomro I.A., 2011. Early wound complications following modified radical mastectomy with axillary clearance. J. Surg. Pak (Int), 16: 4.

Davis G.B., Peric M., Chan L.S., Wong A.K. and Sener S.F., 2013. Identifying risk factors for surgical site infections in mastectomy patients using the National Surgical Quality Improvement Program database. Am. J. Surg., 205(2):194-9.

Ferlay J., Steliarova-Foucher E., Lortet-Tieulent J., Rosso S., Coebergh J., Comber H., Forman D. and Bray F. Cancer incidence and mortality patterns in Europe: Estimates for 40 countries in 2012; European Journal of Cancer 2013; 49: 1374- 1403.

Ghosh S., Sarkar S., Simhareddy S., Kotne S., Rao P.B. and Turlapati S.P., 2013. Clinico-morphological profile and receptor status in breast cancer patients in a South Indian institution. Asian Pacific Journal of cancer prevention: APJCP, 15(18): 7839-7842.

Haagensen C.D., 1971. Diseases of the Breast, 2nd edn. Philadelphia: WB Saunders.

Hussain M.A., Sawkat A., Tyagi S.P. and Reza H., 1994. Incidence of cancer breast at Aligarh. J Indian Med Assoc., 92: 296-297.

Kumar S., Lal B. and Misra M.C., 1995. Post-mastectomy seroma: a new look into the aetiology of an old problem. J. RColl Surg Edinb, 40:292-4.

Prospero E.A., Cavicchi M.S. and Bacelli M., 2006. Surveillance for surgical site infection after hospital discharge: a surgical procedure-specific perspective. Infect Control Hosp Epidemiol. 2006. 27:1313-1317. 
CHANDRAKAR AND SHINDE: RELATION OF BODY MASS INDEX AND EARLY COMPLICATIONS FOLLOWING...

Raju G.C. and Naraynsingh V., 1989. Breast cancer in West Indian women in Trinidad. Trop Geogr Med., 41: 257-260.

Ruvalcaba-Limón E., Robles-Vidal C. and Poitevin-Chacón A., 2006. Complications after breast cancersurgery in patients treated with concomitant preoperative chemoradiation: a case-control analysis. Breast Cancer Res Treat. 95:147-152.

Sandhu D.S., Sandhu S., Karwasra R.K. and Marwah S., 2010. Profile of breast cancer patients at a tertiary care hospital in north India. Indian J. Cancer. 47:16-22.

Shaikh Fazal B., Memon Akbara A. and Kumar M., 2014. Complications of modified radical mastectomy in carcinoma breast patients. Medical Channel. JanMar 2014; 20(1):43-46.

Sharma V.M., Akruwala S.D. and Dave R.I., 2013. Presentation and Management of Breast Cancer Patients in A Newly Started Medical College Hospital. Sch. J. App. Med. Sci., 1(5):522-526.
Thompson A.M. How I do it. Axillary node, clearance for breast cancer. J.R. Coll Surg Edinb 1999; 44: 1117.

Hynes D.M., Weaver F., Morrow. Breast cancer trends and outcomes: results from a National Department of Veterans Affairs study. J. Am. Coll. Surg. 2004. 198: $707-16$.

Weiss J.R., Moysich K.B. and Swede H., 2005. Epidemiology of male breast cancer. Cancer Epidemiol Biomarkers Prev., 14.

Zieliński J., Jaworski R., Irga N. and Kruszewski J. Analysis of selected factors influencing seroma formation in breast cancer patients undergoing mastectomy. Arch Med Sci , February 2013; 8692.

Zieliński J., Jaworski R., Irga N. and Kruszewski J., 2013. Analysis of selected factors influencing seroma formation in breast cancer patients undergoing mastectomy. Arch. Med. Sci., February 2013: pp.86-92. 